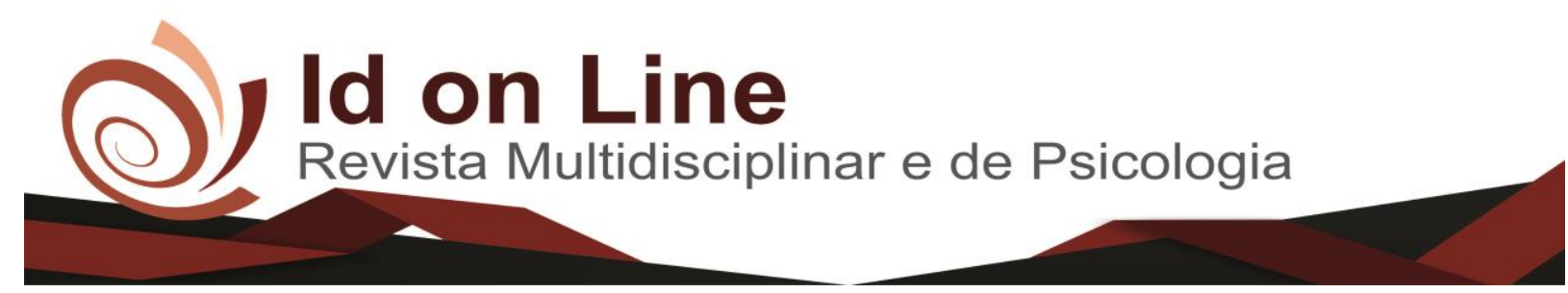

Artigo de Revisão

\title{
Os 7 Ps como Ferramenta para aumentar a lucratividade
}

\author{
Marcielly Hübner ${ }^{l}$; Mariana Emídio Oliveira Ribeiro ${ }^{2}$; Anna Ariane Araújo de Lavor ${ }^{3}$; \\ Antônio Carlos Alves da Silva
}

\begin{abstract}
Resumo: Com o crescimento do setor de serviços, o marketing tem se tornado uma ferramenta muito importante para os profissionais dessa área. Neste artigo procurou-se demonstrar a importância da aplicação do Marketing no setor de serviços, com foco nos 7 Ps do composto de marketing de serviços, como estratégia para garantir o sucesso de novas prestadoras, e para melhorar a prestação de serviços de empresas que estão no mercado há algum tempo. Utilizou-se de revisão de literatura para comprovar a importância dessa estratégia de marketing no setor de serviços, através de citações retiradas de livros e artigos de quem estuda e dedica-se a esta área. Verificou-se que existe a necessidade de uma propagação do marketing no setor, devido os empresários acreditarem que o marketing é apenas para produtos, e devido à alta concorrência, para que haja uma maior competição no mercado, e que com a correta aplicação da estratégia, gere maior satisfação nos clientes, com entrega de serviços de maior qualidade.
\end{abstract}

Palavras-chave: Marketing, Serviços, Estratégia, Cliente.

\section{The $7 \mathrm{P}$ as a Tool to increase profitability}

\begin{abstract}
With the growth of the service sector, marketing has became a very important tool for the professionals in the area. In this article we tried to demonstrate the importance of the application of marketing in the service sector, focusing on the 7 Ps of the service marketing composite, as a strategy to ensure the success of new providers, and to improve the service delivery of companies that have been on the Market for some time ago. It was used a literature review to prove the importance of this marketing strategy in the services sector, through citations taken from books and articles of those who study and dadicates to this area. There is a need for a marketing spread in the sector, because businessmen believe that marketing is for products only, and because of the high competition, so that there is a greater competition in the market, and that with the correct application of the strategy, generates greater satisfaction in the clients, with delivery of services of higher quality.
\end{abstract}

Keywords: Marketing, Services, Strategy, Customer.

\section{Introdução}

O setor de serviços está se expandindo, tornando sua participação mais expressiva na economia, em alguns paises chega a representar mais de $67 \%$ de seu PIB, segundo IBGE. Com aumento anual de profissinais no mercado, é gerada grande concorrecia no setor de

\footnotetext{
${ }^{1}$ Graduanda em Administração pela Faculdade de Alta Floresta FAF. Contato: madrid.karina@ outlook.com

${ }^{2}$ Mestranda em Ambiente e Desenvolvimento pala UNIVATES. Contato: mariana_meo@ @otmail.com;

${ }^{3}$ Mestranda em Ambiente e Desenvolvimento pala UNIVATES. Contato: annaariane@ hotmail.com;

${ }^{4}$ Mestrando em Ambiente e Desenvolvimento pala UNIVATES. Contato: acas-acas@ hotmail.com;

1 Id on Line Rev. Mult. Psic. V.11, N. 38. 2017 - ISSN 1981-1179

Edição eletrônica em http://idonline.emnuvens.com.br/id
} 
serviços. Dessa forma, profissinais da area de servicos como medicos, contadores, auditores, estão aplicando tecnicas mercadologicas em seus negocios. Essa abertura paro o marketing em serviços se dá tambem devido aos clientes que estarem sempre em busca de um atendimento melhor, personalizado, de maior qualidade, principalmente por se ter muitos profissionais no mercado, mas poucos com boa capacitação.

Atualmente o marketing de serviços tem papel fundamental no sucesso das empresas. Suas diferenças para o marketing de bens são: intangibilidade, heterogeneidade, perecibilidade, e a simultaneidade. Essas diferenças trazem a necessidade de profissionais de merketing e de etrategias especificas, tendo como principal estratégia os 7 Ps do composto de marketing de serviços.

Diante disso, levantou-se o seguinte questionamento: Como os 7 Ps do marketing gera aumento na lucratividade?

Com a implantação dos 7 Ps como estratégia de marketing e posicionamento, busca-se o aumento na lucratividade; a fidelização de clientes devido a profissionais qualificados e a promoção dos serviços; a elaboração da estratégia de preços que agrade o consumidor; um posicionamento e um ambiente físico que torne a prestação de serviço ágil e gere a satisfação do cliente.

Os objetivos que conduziram a pesquisa foram: Verificar se a implantação dos 7 Ps gera aumento na lucratividade; identificar como a estratégia dos 7 Ps ajuda a fidelizar os clientes; analisar as variáveis para formação de preços de forma a ter boa lucratividade; Verificar a eficiência no posicionamento do serviço de acordo com a estratégia dos 7 Ps.

O intuito deste estudo foi proporcionar conhecimento sobre aplicação de estratégias de marketing no setor de serviços, para auxiliar na fidelização dos clientes e ger lucratividade, de maneira que possam concorrer amplamente com as demais prestadoras de serviços, oferecendo mais qualidade e maior atenção as necessidades dos cliente..

\section{Embasamento Teórico}

Segundo Las Casas (2006, p. 53) "Estratégia de marketing de serviços refere-se à posição que a empresa deseja alcançar no futuro e o que deve fazer para a conseguir, considerando-se determinado ambiente de atuação". Diversas variáveis podem influenciar na 
aquisição ou prestação de um determinado serviço, como: economia, tecnologia, sociedade, cultura e política. Essas variáveis podem significar uma oportunidade ou uma ameaça, dependendo da capacidade da gerencia de trata-la adequadamente (COBRA; ZWARG, 1986).

Diferente de empresas de produtos, o meio ambiente tem ação muito rápida sobre as empresas de serviço. Dessa forma uma prestadora está constantemente em ameaça. Com o avanço tecnológico, as inovações e a concorrência, um serviço pode se tornar obsoleto, assim um serviço deve estar em constante atualização para suprir as necessidades de sus consumidores (COBRA; ZWARG, 1986).

Para a comercialização de um serviço, não basta decidir apenas sobre características como qualidade, embalagens, marcas, etc. Deve ser definido como será feito o serviço, onde e por quem. Dessa forma, utilizando a estratégia dos 7 Ps, de forma coerente entre as etapas, será possível desenvolver táticas de marketing de serviço eficazes para a satisfação dos consumidores (LAS CASAS, 2006).

\footnotetext{
Os serviços oferecidos por uma empresa devem ser cuidadosamente planejados e, acima de tudo, oferecidos com qualidade. Um serviço bem feito gera satisfação aos clientes atendidos, que voltam a comprar ou indicam outros de seu relacionamento. Com isso, aumenta a demanda e os lucros aumentam. (LAS CASAS, 2006, p. 89)
}

Segundo Cobra (1986) as empresas dever criar e oferecer todas as facilidades possíveis para os consumidores, como: oferecer estacionamento, serviços de entrega, cartões de credito, atendimento rápido, orientações em geral, etc.

Para maior satisfação dos clientes, é preciso que ele perceba o serviço em sı e a empresa deve garantir que ele percebe o nível de atendimento recebido. Os consumidores possuem muitas expectativas diante dos serviços e suas necessidades. Se suas expectativas não forem supridas, pode causar o fracasso de um empreendimento. Um serviço que tenha seu nível de qualidade e agilidade diminuído pode prejudicar a lealdade dos clientes (LAS CASAS, 2006).

O primeiro passo o posicionamento de um serviço, é definir o perfil, do comprador para identificar nichos ainda não explorados. Para isso é feita analise de cinco forças: concorrentes potenciais; fornecedores; substituições; clientes; e concorrente. Essas forças influenciam nos preços, custos e requerem investimentos, portanto, determinam a rentabilidade do setor (COBRA; ZWARG, 1986). 
Os clientes possuem muita dificuldade em considerar os preços dos serviços, pois não possuem uma padronização e variam de profissional para profissional. Devido a não padronização, é possível ter muita flexibilidade na configuração de um serviço, criando heterogeneidade na oferta. Uma forma de definir um preço, é determinar um objetivo, sendo os principais: aumento nos lucros; e aumento nas vendas. Definido o objetivo, é necessário fazer análise de custos, curva de demanda, elasticidade de preços, concorrência, posição operacional e composto de marketing (LAS CASAS, 2006).

\begin{abstract}
O preço deve estar intimamente ligado a qualidade, mas não a qualidade apenas intrínseca do que o serviço é, do que ele faz, mas do que o cliente espera que o serviço faça por ele. Muitas vezes um serviço "não tem preço", dependendo da necessidade que um cliente tem dele. Assim, o conceito de caro e barato é extremamente relativo: relativo a satisfação de necessidades latentes ou urgentes. (COBRA; ZWARG, 2006, p. 93)
\end{abstract}

O ambiente físico é um componente de comunicação de grande importância. Ele referese ao estabelecimento onde será prestado o serviço. Nele contém toda a comunicação visual da empresa. O cliente, ao entrar no estabelecimento, irá buscar evidencias visuais para apoiar sua decisão de ir até determinado prestador. Portando o administrador de observar se seu ambiente está de acordo com as expectativas do público-alvo, analisando limpeza, disposições de moveis, layout, entre outros fatores (LAS CASAS, 2006).

Para Lovelock, Wirtz e Hemzo (2011, p. 28) “os 7 Ps do composto de 1 serviços, englobam o conjunto de variáveis que representam as decisões gerenciais de marketing necessárias para criar estratégias viáveis, voltadas ao atendimento das necessidades dos clientes de modo lucrativo em um mercado competitivo".Os 7 Ps são:

- Produto: criar um concito de serviços que ofereça valor significativo aos clientes e que satisfaça melhor suas necessidades do que a concorrência;

- Praça: atualmente o tempo se tornou muito importante, por isso a agilidade e conveniência do local e hora de atendimento são fatores que determinam uma eficaz distribuição e entrega de serviços;

- Preço: é um mecanismo pelo qual gera receita para cobrir custos e ter lucro. A estratégia de preço é ajustada constantemente de acordo com vários fatores sociais e econômicos; 
- Promoção: desempenha três papeis fundamentais: prover informações sobre produtos e serviços; persuadir o público alvo quanto o produto; e incentiva-lo a agir em momentos específicos;

- Processo: para satisfazer os clientes é necessário elaborar, planejar e implementar processos eficazes, caso contrário pode gerar perca de tempo e experiências frustrantes;

- Ambiente Físico (Physical Environment): um ambiente bem aparentado, funcionários uniformizados e boa localização, sugerem um serviço mais eficiente;

- Pessoas: Funcionários talentosos e motivados, que se comunicam bem com os clientes, que passam informações necessárias e corretas, representam vantagem competitiva.

Os serviços consistem em um produto que atende as necessidades do consı

variedade de serviços que agregam valor e que ajudam os clientes a usar o produto de forma mais eficaz. Na atualidade, o tempo é muito importante para os consumidores. Portanto, os clientes buscam empresas que ofereçam horários de atendimento ampliados. mesmo que tenham que pagar um pouco mais, mas que satisfaça sua necessidade. Alé serviço, os clientes também avaliam os custos extras de deslocamento até a empresa, tempo, esforço físico e mental, para definir se aquela empresa é conveniente para suas necessidades (LOVELOCK; WIRTZ; HEMZO, 2011).

Para Lovelock, Wirtz e Hemzo (2011, p. 379) "a fidelidade de marca significa mais do que o comportamento e abrange a preferência, amizade e intenções futuras”.

\footnotetext{
A base da verdadeira fidelidade está na satisfação do cliente, para a qual a qualidade de serviço é um componente fundamental. Cientes muito satisfeitos ou mesmo encantados tem mais probabilidade de serem defensores leais da empresa, consolidarem compras com um só fornecedor e disseminar o boca a boca positivo. (LOVELOCK; WIRTZ; HEMZO, 2011, p. 394)
}

Segundo estudos realizados por Reichheld e Sasser apud LOVELOCK, WIRTZ e HEMZO (2011), quanto maior o tempo de fidelidade de um cliente, mais lucrativo será atende-lo. Eles apontam quatro fatores que geram esse crescimento do lucro. São eles:

- Aumento no número de compras: clientes empresariais em crescimento; aumento no número de membros das famílias; aumento da renda. 
- Redução no custo operacional: clientes experientes tem menor necessidade de assistência e cometem menos erros nos processos operacionais.

- Indicações: clientes que indicam o serviço para outras pessoas tornam-se propaganda gratuita, aumentando o número de clientes sem aumento no custo de propagandas.

- Preços mais elevados: clientes fiéis costumam pagar preços normais por estarem satisfeitos com os serviços, e por confiarem no fornecedor, não se importam em pagar mais em épocas de pico ou em urgências.

As principais falhas, que levam a perca de um cliente, são: erros na prestação de serviço, erro de faturamento; falta de conhecimento; preços elevados inconveniência de local e/ou horário de funcionamento; espera pelo serviço, e concorrência com melhores condições de atendimento (LOVELOCK; WIRTZ; HEMZO, 2011).

De acordo com a estratégia dos 7 Ps, para a prevenção dos erros citados acima, e para aumento de clientes e lucratividade, deve-se escolher um bom local para a prestacão do serviço, onde será de fácil acesso para os clientes fies e também que propo possibilidade de clientes novos surgirem, sendo um lugar com grande movimentação de pessoas, ambiente bem estruturado, organizado e agradável, em que possam chegar rapidamente e que o serviço será feito dentro do prazo que melhor se encaixe na necessidade do cliente e com qualidade. Profissionais bem equipados, instruídos e receptivos, que entendam todo o processo do serviço que está sendo prestado, explique corretamente para o cliente o quê e porquê será feito, demonstram a qualidade do serviço e passa confiança para o cliente. Entendendo tudo o que será feito, o cliente tem melhor possibilidade de analisar o valor que está sendo cobrando e perceber se o valor é abusivo ou injusto (LOVELOCK; WIRTZ; HEMZO, 2011).

O apreçamento de serviços, é a parte mais complexa do marketing de serviços, pois não há padronização dos preços e variam a cada profissional. Seu nível de preço é ajustado constantemente, de acordo com variáveis como lugar e hora, tipo de cliente, demanda e capacidade disponível. Inicialmente a empresa deve definir seu objetivo de apreçamento, sendo os mais comuns gerar receitas e lucros e gerar demanda e desenvolver uma base de usuários. Definido o objetivo, três fatores podem auxiliar na formação do preço: custo do fornecedor, preços da concorrência, e o valor para o cliente. Os custos definem o valor mínimo do serviço, e o valor percebido pelo cliente definirá um teto, o preço máximo que ele 
pagará. Preço cobrado pelos concorrentes determina onde o preço pode ser estabelecido de acordo com o objetivo definido (LOVELOCK; WIRTZ; HEMZO, 2011).

Ao determinar um valor para o serviço, é necessário analisar se o cliente percebe que os benefícios que está recebendo são maiores que os custos que está tendo. Para serviços de credibilidade, onde não é possível avaliar a qualidade mesmo após o consumo, a dificuldade é ainda maior, sendo necessária explicações pessoais, comunicar fatores c experiência profissional, para que o cliente compreenda o que está recebendo pelo preço que ele está pagando (LOVELOCK; WIRTZ; HEMZO, 2011).

“É essencial que as empresas façam pesquisas para identificar o valor atribuído a seus serviços. A pesquisa permite identificar quais atributos adicionam valor a sua oferta e quais são percebidos como desnecessários, que apenas aumentam os custos" (LOVELOCK; WIRTZ; HEMZO, 2011, p. 178).

Para os clientes as definições de valor podem ter ao teor pessoal, sendo terminados por quatro expressões: valor é preço baixo; valor é o que quero de um serviço; valor é a qualidade do serviço pelo preço que pago; e valor é o que obtenho pelo que dou. É importante lembrar que um preço elevado gera maior exigência do consumidor, e um preço muito baixo pode dar impressão de serviço de baixa qualidade (LOVELOCK; WIRTZ; HEMZO, 2011).

Empresas com serviços com pouco ou nenhum diferencial, devem monitorar os concorrentes e determinar seus preços de acordo com isso. É preciso ter cuidado para não estabelecer preços mais baixos que o necessário. É importante levar em conta o custo para o cliente da oferta competitiva, os custos financeiros e não monetários para então comparar com o provedor. Também deve comunicar aos clientes os custos financeiros e não financeiros envolvidos na sua oferta e na do concorrente (LOVELOCK; WIRTZ; HEMZO, 2011).

\footnotetext{
Um gerenciamento de receitas eficaz requer dois ou mais segmentos que atribuam valores diferentes ao serviço e tenham elasticidade de preço diferente. Para alocar capacidade e determinar seu preço com eficácia, o gerente de receita precisa determinar o grau de sensibilidade da demanda em relação ao preço e quais receitas liquidas serão geradas a diferentes preços para cada segmento-alvo. (LOVELOCK; WIRTZ; HEMZO, 2011, p. 181)
}

Um mesmo serviço pode ter valores variados para cada clientes, desta forma é preciso segmentar os clientes e criar barreiras de tarifas. Essas barreiras são regras de formação de preço em função de atributos que variam para atender diferentes clientes. As barreiras auxiliam as empresas a oferecer preços mais baixos a quem está disposto a aceitar mais 
restrições a suas comprar, e a evitar que clientes que pagam por mais, se aproveitei das cesta de serviços mais baratas. As barreiras podem ser: físicas (diferenças tangíveis en

relacionado aos diferentes preços); e não físicas (características de consumo, de transação ou de consumidor) (LOVELOCK; WIRTZ; HEMZO, 2011).

Atualmente, a cobrança de taxas que as vezes tem pouco a ver com o uso do serviço, assim como adicionar multas e penalidade, tem tido um crescimento considerável, principalmente do setor bancário, gerando uma percepção injusta para os cliertas Drám am todos os setores, é possível estabelecer taxas e penalidades que não prejudiq como a cobrança por não comparecimento, quando o cliente reserva um serviço, mas não comparece. Sendo bem explicada a cobrança, devido a perca do serviço que a empresa terá, o cliente aceitar pagar as taxas (LOVELOCK; WIRTZ; HEMZO, 2011).

Devido ao crescimento da concorrência no setor de serviços, torna-se cada vez mais importante a diferenciação dos produtos de maneira significativa para os clientes. Eles apenas mudam de fornecedor em casos de problemas ou surgimento de soluções mais vantajosas, pois uma mudança pode gerar custos para o cliente. Os gerentes devem utilizar das várias técnicas de pesquisa para saber quais características despertam o interesse do consumidor e desenvolver o melhor plano estratégico (LOVELOCK; WIRTZ; HEMZO, 2011).

\footnotetext{
A estratégia de posicionamento preocupa-se em criar, comunicar e manter diferenciais que serão notados e valorizados pelos consumidores com que a empresa mais gostaria de manter um relacionamento de longo prazo e que foram selecionados como público-alvo. O posicionamento eficaz requer que os gerentes compreendam, por meio de pesquisas as preferencias desse público, sua concepção de valor e as características das ofertas concorrentes. (LOVELOCK; WIRTZ; HEMZO, 2011, p. 76)
}

O posicionamento de serviços geralmente está associado a atributos de preço e produto, processo de serviço (conveniência, facilidade de uso), distribuição e entrega, ambiente de serviço, e pessoal de atendimento. Como o setor de serviços possui grande diversidade tanto de serviços quanto de clientes, é necessário que a prestadora tenha um foco para atingir vantagem competitiva. São quatro as estratégias de foco:

- Totalmente focada: fornece uma faixa limitada de serviços, a um segmento especifico de mercado;

- Focada em mercado: tem segmento estreito, mas possui amplo leque de serviços; 
- Focada em serviços: oferece um leque estreito de serviços a um mercado razoavelmente amplo.

- Sem foco: leque de serviços e segmento de mercado totalmente amplo.

É recomenda a utilização apenas de uma das três primeiras estraté: estratégia sem foco pode causar a perca de recursos e baixa qualidade no atenaımento, aeviao a empresa ter de investir muito em funcionários para um atendimento de qualidade (LOVELOCK; WIRTZ; HEMZO, 2011).

\begin{abstract}
A segmentação representa um dos maiores conceitos de marketing. A capacidade que diferentes empresas de serviços têm de atender diferentes tipos de cliente varia muito. Por conseguinte, em vez de tentar competir em todo o mercado, talvez contra concorrentes superiores, cada empresa deve adotar uma estratégia de segmentação, identificando as partes do mercado que ela pode atender melhor. (LOVELOCK; WIRTZ; HEMZO, 2011, p. 79)
\end{abstract}

Após selecionado um segmento-alvo, é necessário identificar os atributos que são importantes para segmentos específicos e como o consumidor percebe a execução desses atributos pelos concorrentes. Entretanto, um mesmo indivíduo pode determinar prioridades diferentes para um atributo dependendo de seu contexto. É importante diferenciar atributos importantes e determinantes. O primeiro, são atributos que devem estar nas características de um serviço, mas que não determina a decisão de compra, já o segundo, são atributos não importantes, mas que permitem os consumidores observar diferenças entre serviços concorrentes (LOVELOCK; WIRTZ; HEMZO, 2011).

\footnotetext{
Uma vez compreendidos os atributos importantes e os determinantes, a gerencia necessita decidir qual nível de serviço a empresa deve oferecer em cada atributo. Os níveis de serviço são comumente usados para segmentar os consumidores de acordo com sua disposição em trocar preço por nível de serviço em ampla variedade de atributos. (LOVELOCK; WIRTZ; HEMZO, 2011, p. 98)
}

O posicionamento tem papel fundamental na estratégia de marketing, pois associa análise de mercado e a competitiva à analise corporativa interna. Essa associação trará como resultado o posicionamento adequado da empresa, que fornecerá todas as informações necessárias para que o cliente tome sua decisão de compra. A análise de posicionamento deve ser feita periodicamente, devido as mudanças no mercado, tecnológicas, e até evolução da empresa (LOVELOCK; WIRTZ; HEMZO, 2011). 
Em uma prestadora de serviços os funcionários interagem diretamente com os clientes para criar o serviço. Sendo assim, para Armstrong e Kotler (2007), além d n 1 n n d marketing, o marketing de serviços requer também marketing interno e market No marketing interno a prestadora deve orientar e motivar seus funcionários para que trabalhem em equipe e satisfaçam os clientes. O marketing interativo define a qualidade de interação entre o prestador e o cliente, quanto mais habilidoso e motivado o funcionário estiver, melhor atenderá o cliente, e maior será sua satisfação (ARMSTRONG; KOTLER, 2007).

Com a grande concorrência da atualidade, muitos profissionais do marketing tem recorrido ao marketing de conquista, onde oferecem descontos, redução de preços e promoções para encorajar novos negócios. Porém essa estratégia só é eficiente no curto prazo, pois os clientes não se tornam fieis, e irão para outra empresa assim que recebem uma nova oferta. Dessa forma, no longo prazo, a retenção do cliente se torna mais eficaz na geração de lucro para a empresa. Empresas que tem como objetivo principal a retenção de clientes são notadas e diferenciadas, com sucesso, de seus concorrentes (HOFFMAN; BATESON; IKEDA; CAMPOMAR, 2012).

Segundo Hoffman (2012), para a retenção de clientes, as táticas a baixo são as mais eficazes.

- Manter perspectiva apropriada: satisfazer as necessidades dos clientes é prioridade, é importante que os funcionários lembrem que cada cliente tem suas necessidades e expectativas e isso definira o desemprenho, a boa comunicação será determinante.

- Lembrar-se dos clientes: manter contado no pós-venda, enviar cartões de aniversario, bilhetes de cumprimentos por conquistas pessoais, acompanhar o desempenho dos serviços prestados. O objetivo é mostrar que a empresa tem interesse pelo bem-estar do cliente.

- Desenvolver relacionamentos de confiança: a especialização do provedor, confiabilidade e interesse e preocupação como o cliente são os principais componentes da confiança.

- Monitorar o processo de prestação de serviço: a busca de opiniões durante o processo cria percepção de confiança e facilita a manutenção de clientes. 
- Auxilio ao cliente: instalar adequadamente equipamentos e ensinar os clientes a usar corretamente ajuda a evitar problemas futuros. No caso de necessidade do cliente, sempre deve-se mostrar disposto a resolver o problema.

O custo de um serviço também pode ser um fator de fidelidade de clientes, por isso é importante definir um preço justo para o que é oferecido. Para determinar o preço de um serviço é preciso analisar a percepção de valor de um cliente, isto é, se o preço que está pagando for maior que os benefícios que ele está recebendo, o cliente não comprar aquele serviço. Também é importante analisar os custos da prestação desse serviço, pois se o preço for menor ou igual aos custos a empresa não terá lucros. Assim a empresa define um teto e um piso, podendo escolher qualquer preço entro eles. Mas é importante lembrar que o preço da concorrência também deve ser analisado, para que se estabeleça um preço competitivo (ARMSTRONG; KOTLER, 2007).

Para o sucesso de uma prestadora de serviços, é preciso que se desenvolva uma estratégia de posicionamento eficaz. Segundo Hoffman (2012, p. 223):

\footnotetext{
O posicionamento eficaz é particularmente crítico para empresas de serviços em que a intangibilidade dificulta a capacidade do cliente para diferenciar uma oferta de serviços de outra. [...] Em última análise, o posicionamento envolve uma combinação estratégica das variáveis do marketing mix da empresa: produto, preço, promoção, praça, instalações físicas, pessoal e processos.
}

As variáveis do mix de marketing são controláveis, e quando efetivament podem compensar os efeitos das variáveis incontroláveis, como: avanços tecnológicos, concorrentes, leis, necessidades dos consumidores, etc. $\mathrm{Na}$ mudança de plano estratégico, muitas empresas falham no longo prazo, na tentativa de se diferenciar dos concorrentes (HOFFMAN; BATESON; IKEDA; CAMPONAR, 2012).

\section{Metodologia}

A pesquisa foi realizada para demonstrar a importância do marketing de serviço e da estratégia dos 7 Ps, suas principais características e explicar como sua aplicação dever ser realizada para gerar bons resultados, sendo realizada através da pesquisa bibliográfica e de método qualitativo.

Sobre a pesquisa bibliográfica, Souza comenta: 
Todo e qualquer trabalho acadêmico requer um conhecimento sobre os livros, artigos, periódicos de modo impresso, eletrônico, etc, sendo imprescindível um processo metodológico, um certo caminho a seguir, como forma de ser racional e econômica para aquele que realiza a pesquisa (SOUZA, 2001, p. 59).

'Para Goldenberg (1997, p. 34) a pesquisa de metodologia qualitativa não se preocupa com os números, mas sim com os fatos. Sendo que os pesquisadores que se utilizam desta metodologia buscam explicar o porquê das coisas, preocupando-se em demonstrar aspectos da realidade que não podem ser computados.

\section{Resultados e Discussão}

O marketing de serviços, assim como de produtos, surge da necessidade de divulgação das empresas e seus serviços, a fim de conquistar clientes, através de uma boa marketing, dando visibilidade aos serviços prestados, a qualidade de atendimento e o interesse em resolver o problema de seus clientes. Diante disso, os objetivos deste trabalho foram: Verificar se a implantação dos 7 Ps gera aumento na lucratividade; identificar como a estratégia dos 7 Ps ajuda a fidelizar os clientes; analisar as variáveis para formação de preços de forma a ter boa lucratividade; verificar a eficiência no posicionamento do serviço de acordo com a estratégia dos 7 Ps.

De acordo com a problemática do assunto discutido Lovelock, Wirtz e Hemzo (2011) mostra que os 7 Ps do marketing deve ser usado como alavancas estratégicas, com um planejamento bem elaborado e eficiente, para que a satisfação do cliente em cada um dos 7 Ps seja satisfatória, podendo gerar aumento de clientes e fidelizações, gerando assim, maior lucratividade para o prestador.

Segundo Lovelock, Wirtz e Hemzo (2011) “o planejamento do compostos de marketing começa com a criação de um conceito de serviço que oferecerá valor para segmentar os consumidores e satisfazer melhor suas necessidades do que as alternativas concorrente". Para o autor, os 7 Ps são variáveis necessárias para criar estratégias viáveis, para que a empresa consiga sanar as necessidades de seus clientes de modo lucrativo, desde que seja bem elaborada e implantada, pois do contrário, poderá surtir efeito negativo. 
Para Kotler e Armstrong (2007) é necessário criar valor para os clientes, sendo necessário, em primeiro lugar, realizar uma pesquisa das necessidades dos clientes, e então elaborar uma estratégia de marketing, com base nos 7 Ps, que criará valor real para o cliente. Gerando satisfação ao cliente, e sua fidelização, tendo aumento nos lucros.

Lovelock, Wirtz e Hemzo (2011) fornece a roda da fidelidade com três fatores para fidelização de cliente, sendo o primeiro segmentar o mercado para equiparar a capacidade da empresa com as necessidades dos clientes, sendo a estratégia de produto, praça processo e preço, gerando serviços de maior qualidade que geram maior satisfação. Segundo é preciso criar vínculos com os clientes para aprofundar o relacionamentos, usando as estratégias de promoção, pessoas e ambiente físico, utilizando de vendas cruzadas ou programas de recompensas. E terceiro identificar e eliminar fatores que resultem em churn, co]

de pessoas, aumentando os custos de troca, e implantar processos de administração de reclamações e recuperação de serviços.

Kotler e Armstrong (2007) dizem que a chave para relacionamentos duradouros é criar valor e satisfação para o cliente. Com variadas opções de serviços, a empresa deve ter um estratégia de preço, produto e promoção bem elaborada, pois irá gerar grande satisfação ao cliente que se tornará fiel.

Para Lovelok (2011) o apreçamento pode ser definido pelas variáveis de lugar e hora de trabalho, demanda, capacidade da empresa, custos, preços concorrentes, e valor para o ciente. Os custos do serviço deve ser tomado como preço mínimo, e a partir daí fazer analises para formar o preço para obter lucros e não perder clientes. É importante deixar claro ao cliente os benefícios que eles está recebendo no serviço, pelo preço que ele está pagando.

Kotler e Armstrong (2007) mostram que o preço tem sido a maior detern cliente comprar um serviço. Diante disso, há empresas dispostas a cobrar preços abaixo do valor de seus serviços para conseguir uma venda. Portanto é preciso avaliar a percepção de valor do cliente em relação ao serviço oferecido, considerar a demanda do mercado, as estratégias e preços dos concorrente, e seus custos para se determinar um preço que agrade o cliente e que se obtenha maior lucratividade.

Segundo Lovelock, Wirtz e Hemzo (2011) a estratégia de posicionamento ajuda na diferenciação de um serviço para o outro. Para um posicionamento eficaz e necessário realizar pesquisas para saber as preferências dos clientes, sua visão de valor e as características de ofertas dos concorrentes. Na estratégia de posicionamento é considerado a praça, o ambiente 
físico e as pessoas. Um local de fácil acesso, bons funcionários, e um ambiente agradável, trará maior satisfação aos clientes gerando fidelidade e lucratividade.

O posicionamento do produto é importante para a fidelização de clientes regulares e para o aumento de clientes no geral. Segundo Hoffman (2007, p. 223) "o posicionamento envolve uma combinação estratégica das variáveis do marketing mix da empresa: produto, preço, promoção, praça, instalações físicas, pessoal e processos”. Para o autor : posicionamento torna a empresa diferente do concorrente para o cliente. Quando as variáveis estão bem combinadas, elas compensam variáveis que a empresa não pode controlar.

\section{Considerações Finais}

A estratégia dos 7 Ps, diante da grande concorrência no mercado de serviços, se torna fundamental para que as prestadoras se mantenha competitivas no mercado, pois com a estratégia definida, a empresa conseguira se posicionar de forma a atrair clientes e ter lucro, oferecendo serviços de qualidade e bom atendimento.

Mas é muito importante os empresários entendam os \& Ps para que elaborem estratégias eficazes, realizando pesquisas de mercado, afim de saber as neressidades dos clientes e sua percepção de valor, assim como saber como as concorren principalmente para a determinação de preço. Com uma estratégia mal elaborada, o efeito pode ser negativo, podendo fazer com que a empresa perca seus clientes, ou não consiga clientes novos.

Com o estudo através de livros, artigos e cases de sucesso, o administrador será capaz de identificar e implantar da melhor formar essas ferramentas garantindo seu espaço e seu lucro no mercado de serviços, e evitando erros em suas estratégias.

\section{Referências}

COBRA, M; ZWARG, F. A. Marketing de Serviços: conceitos e estratégias. São Paulo: McGraw-Hill, 1986. 
FALCHI, P. Características do marketing de serviços em comparação aos bens de consumo. Implantando Marketing, 2012. Disponível em: < http://www.implantandomarketing.com/caracteristicas-do-marketing-de-servicos-e-bens-deconsumo/ > . Acesso em: 20 de maio de 2017.

HOFFMAN, K; BATESON, J; IKEDA, A; CAMPONAR, M. Princípios de marketing de serviços: conceitos, estratégias e casos. São Paulo: Cencage Learning, 2012.

KOTleR, P.; ARMSTRONG, G. Princípios de Marketing. 12a ed. São Paulo: Pearson Prentice Hall, 2007.

LAS CASAS, A. L. Marketing de Serviços. 4a ed. Ribeirão Preto: Editora Atlas, 2006.

LOVELOCK, C; WIRTZ, J; HEMZO, M. Marketing de serviços: pessoas, tecnologia e estratégia. 7a ed. São Paulo: Pearson Prentice Hall, 2011.

VERAS, J. G. F; COSTA, J, O. Análise dos 8 P's do marketing de serviços na empresa plano de assistência familiar. Patos: Universidade Estadual da Paraíba Campus VII, 2014. Disponível em: < http://dspace.bc.uepb.edu.br/jspui/bitstream/123456789/965/1/PDF\%20\%20Jos\%C3\%A9\%20Gustavo\%20Fragoso\%20de\%20Veras.pdf >. Acesso em : 22 de maio de 2017.

Como citar este artigo (Formato ABNT):

HÜBNER, Marciely; RIBEIRO, Mariana E.O.; LAVOR, Ariane A. de; SILVA, Antônio C. A. da. Os 7 Ps como Ferramenta para aumentar a lucratividade. Id on Line Revista Multidisciplinar e de Psicologia, 2017, vol.11, n.38, p.1-15. ISSN: 1981-1179.

Recebido: 22.08 .2017

Aceito: 23.08.2017 